\title{
Superior postoperative pain relief with thoracic epidural analgesia versus intravenous patient-controlled analgesia after minimally invasive pectus excavatum repair
}

Thomas Weber, MD, DEEA, ${ }^{a}$ Johanna Mätzl, MD, ${ }^{a}$ Alexander Rokitansky, MD, ${ }^{\mathrm{b}}$ Walter Klimscha, MD, ${ }^{\mathrm{a}}$ Konrad Neumann, PhD, ${ }^{c}$ and Engelbert Deusch, MD, ${ }^{d}$ for the Medical Research Society, Vienna, Danube City

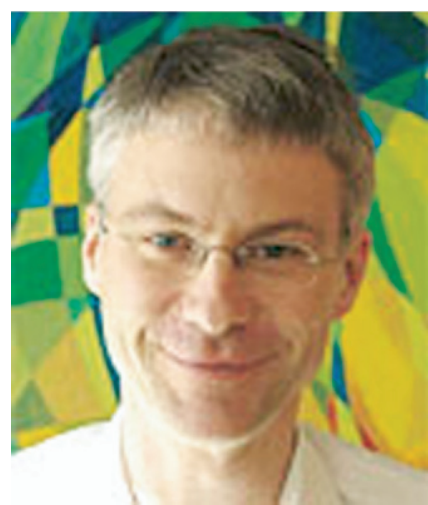

Dr Weber

Objective: Minimally invasive pectus excavatum repair is a common and painful surgical procedure in children and adolescents. Adequate postoperative pain therapy is important far beyond the immediate postoperative period because sensitization to painful stimuli can cause chronic pain or higher pain levels during subsequent surgical procedures. Although data in adults favor thoracic epidural anesthesia for pain control in thoracotomy, data for adolescents and children are scarce. We tested the hypothesis that pain relief with thoracic epidural analgesia was superior to that with intravenous patient-controlled analgesia after minimally invasive pectus excavatum repair in children and adolescents.

Methods: We performed a prospective randomized trial with adolescents who had undergone minimally invasive pectus excavatum repair to compare postoperative pain using two different postoperative pain therapy settings: intravenous patientcontrolled analgesia $(n=20)$ with morphine versus continuous thoracic epidural analgesia $(\mathrm{n}=20)$ with $0.2 \%$ ropivacain containing $2 \mu \mathrm{g} / \mathrm{mL}$ fentanyl.

Results: Forty patients (32 male and 8 female patients) aged 10 to 28 years were studied. The thoracic epidural analgesia group showed lower pain scores $(P<$ $.0001)$ and required less additional pain medication in conjunction with greater

From the Medical Research Society, Vienna, Danube City; Department of Anesthesiology and Intensive Care, ${ }^{\mathrm{a}}$ Sozialmedizinisches Zentrum Ost-Donauspital, Vienna, Austria; the Department of Pediatric Surgery, ${ }^{\mathrm{b}}$ Sozialmedizinisches Zentrum Ost-Donauspital, Vienna, Austria; and Charité-University of Medicine Berlin, ${ }^{\mathrm{c}}$ Institute for Clinical Epidemiology, Berlin, Germany; and the Department of Special Anesthesiology and Pain Therapy, ${ }^{\mathrm{d}}$ Vienna Medical University, General Hospital Vienna, Vienna, Austria.

AstraZeneca, Bristol Myers-Squibb, and Smiths Medical Austria supported the study with an unrestricted grant.

Received for publication Nov 24, 2006; revisions received March 3, 2007; accepted for publication May 11, 2007.

Address for reprints: Thomas Weber, MD, DEEA, Medical Research Society, Vienna, Danube City, at the Sozialmedizinisches Zentrum Ost-Donauspital, Department of Anesthesiology and Intensive Care, Langobardenstrasse 122, A-1220 Vienna, Austria (E-mail: thomas.weber@wienkav.at).

J Thorac Cardiovasc Surg 2007;134:865-70 $0022-5223 / \$ 32.00$

Copyright $(92007$ by The American Association for Thoracic Surgery

doi:10.1016/j.jtcvs.2007.05.050 well-being postoperatively $(P<.0001)$ compared with patients receiving patientcontrolled intravenous morphine. There was no significant difference regarding the incidence of sedation $(P=.38)$, nausea $(P=.10)$, and pruritus $(P=.72)$ in both groups.

Conclusions: For adolescents undergoing minimally invasive pectus excavatum repair, thoracic epidural analgesia was superior to intravenous patient-controlled analgesia for postoperative analgesia, resulting in lower postoperative pain scores in conjunction with greater well-being.

$\mathrm{P}$ ectus excavatum is the most common chest wall deformity in children, with an incidence of approximately 1 in 700 births. Since 1987, a minimally invasive approach first described by Nuss and coworkers ${ }^{1}$ has gained popularity. ${ }^{2,3}$ A convex retrosternal stainless-steel bar is placed and positioned between the midaxillary lines at the level of maximal pectus depth to correct the defect. Despite this minimally invasive technique, pectus excavatum operations are very painful procedures and postoperative pain management can be difficult. ${ }^{3}$ Adequate postoperative pain therapy is important far beyond the immediate postoperative period because sensitization to painful stimuli can cause chronic pain states or higher pain levels during subsequent surgical procedures. Nearly $80 \%$ of patients undergoing this procedure are children or adolescents. ${ }^{4}$ Although perioperative thoracic epidural analgesia (TEA) is recommended by many authors, ${ }^{5,6}$ others use intravenous patient-controlled analgesia $(\mathrm{PCA})^{7,8}$ for postoperative analgesia after 


\section{Abbreviations and Acronyms \\ PCA $=$ patient-controlled analgesia \\ TEA $=$ thoracic epidural analgesia \\ VAS $=$ visual analog scale}

this surgical procedure. To date, no study is available that compares different types of pain management for pectus excavatum repair in a randomized prospective manner.

The aim of the current prospective randomized study was to compare postoperative pain relief, subjective wellbeing, and incidence of side effects in two different pain therapy settings: intravenous PCA versus TEA in adolescents undergoing minimally invasive pectus excavatum repair.

\section{Materials and Methods Study Design}

This prospective randomized cohort study was performed on patients (age $\geq 10$ years) undergoing minimally invasive pectus excavatum repair at the Donauspital, Vienna, Austria, between October 2003 and April 2006 after obtaining approval from the institutional review board and written informed consent from each patient or his or her legal representative.

From previous data of this institution, we determined a minimal sample size of 17 patients per group to detect a difference between the 2 treatment groups of 2 visual analog scale (VAS) units with an estimated standard deviation of 2 by setting the $\beta$ value at $80 \%$ and the $\alpha$ value at .05 or less.

\section{Participants}

Of 52 patients eligible for the study, 12 refused participation. Forty patients (32 male and 8 female patients aged 10-28 years) were included.

Randomization into the 2 treatment groups (intravenous PCA $[\mathrm{n}=20]$ and TEA $[\mathrm{n}=20]$ ) was done by using a computergenerated randomization list. Exclusion criteria were the refusal of a thoracic epidural catheter, pregnancy, bleeding history, and regular medication interfering with blood coagulation, except lowdose heparin. Dropout criteria in the TEA group were catheter dislocation, inflammation signs, or both at the catheter insertion site.

\section{Anesthesia}

Patients in the TEA group received a thoracic epidural catheter in the operating room immediately before surgical intervention after achievement of local anesthesia by using a median approach at Th6/7 or Th7/8, corresponding to the probable insertion site of the steel bar. Epidural space was identified by a loss-of-resistance technique with saline solution. The catheter was advanced $3 \mathrm{~cm}$ into the epidural space. A test dose of $2 \mathrm{~mL}$ of lidocaine $2 \%$ with epinephrine 1:200,000 was applied before using the epidural catheter to rule out intrathecal or intravasal malposition.

Induction of anesthesia was performed with $2.5 \mathrm{mg} / \mathrm{kg}$ propofol, $3 \mu \mathrm{g} / \mathrm{kg}$ fentanyl, and $0.6 \mathrm{mg} / \mathrm{kg}$ rocuronium for tracheal intubation.
Anesthesia was maintained with 6 to $8 \mathrm{mg} \cdot \mathrm{kg}^{-1} \cdot \mathrm{h}^{-1}$ propofol, normoventilation with air/oxygen mix at a fraction of inspired oxygen of $30 \%$, and repetition doses of 1 to $2 \mu \mathrm{g} / \mathrm{kg}$ fentanyl and $0.1 \mathrm{mg} / \mathrm{kg}$ rocuronium at the discretion of the attending anesthesiologist. Fifteen minutes before the end of the operation, each patient received an intravenous bolus of $15 \mathrm{mg} / \mathrm{kg}$ acetaminophen.

After the induction of anesthesia, patients in the TEA group received a bolus of $0.2 \mathrm{~mL} / \mathrm{kg}$ ropivacain $0.2 \%$ containing 2 $\mu \mathrm{g} / \mathrm{mL}$ fentanyl, followed by a continuous rate of $0.2 \mathrm{~mL} / \mathrm{h}$ of the same mixture administered epidurally. All patients were extubated in the operating room.

\section{Postoperative Analgesia}

Both groups received $1 \mathrm{mg} / \mathrm{kg}$ diclofenac administered intravenously every 8 hours until the fourth postoperative day.

Intravenous PCA group. Each patient could self-administer $0.02 \mathrm{mg} / \mathrm{kg}$ morphine as a bolus through a PCA pump (Cadd Prism; Smith Medical, Brunn am Gebirge, Austria); a lockout time of 6 minutes and a maximal rate of 6 boluses per hour was set. No additional continuous rate was applied.

TEA group. Each patient received ropivacain $0.2 \%$ containing $2 \mu \mathrm{g} / \mathrm{mL}$ fentanyl continuously at a rate of 0.2 $\mathrm{mL} \cdot \mathrm{kg}^{-1} \cdot \mathrm{h}^{-1}$ through the thoracic epidural catheter. Removal of the epidural catheter was performed on the fourth postoperative day (96 hours).

Rescue medication in case of break-through pain. At a VAS pain score of greater than 4, patients of both groups received an additional $15 \mathrm{mg} / \mathrm{kg}$ acetaminophen administered intravenously (maximum of 4 times a day). If, despite this, break-through pain was still experienced, additional opioids (1.5-mg piritramide boluses administered intravenously) were given in the PCA group, whereas patients in the TEA group received an additional epidural bolus of $0.1 \mathrm{~mL} / \mathrm{kg}$ ropivacain $0.2 \%$ with $2 \mu \mathrm{g} / \mathrm{mL}$ fentanyl.

Supplemental oxygen was started at an oxygen saturation of less than $94 \%$ during spontaneous ventilation.

\section{Surgical Procedure}

A modification of the original method ${ }^{1}$ using a thoracoscope for the creation of the retrosternal tunnel was used. ${ }^{9}$ Except for in 1 patient assigned to the TEA group, all procedures were primary operations.

\section{Data Collection}

Pain as a primary end point was assessed by using an 11-point $\operatorname{VAS}(0=$ no pain and $10=$ maximal pain $)$ at the end of anesthesia (0 hours), every 12 hours until the 96-hour postoperative time point, and at discharge. Additional pain medication requests were assessed by the nurse on the ward.

Subjective well-being was assessed by using a 101-point VAS $(0=$ no well-being and $100=$ perfect well-being $)$ on the day of the operation, the first and fifth postoperative days, at discharge, and 3 months after the operation.

\section{Side Effects}

Sedation was assessed on a numeric rating scale between 0 and $2(0=$ no sedation and $2=$ deep sedation by a nurse on the 


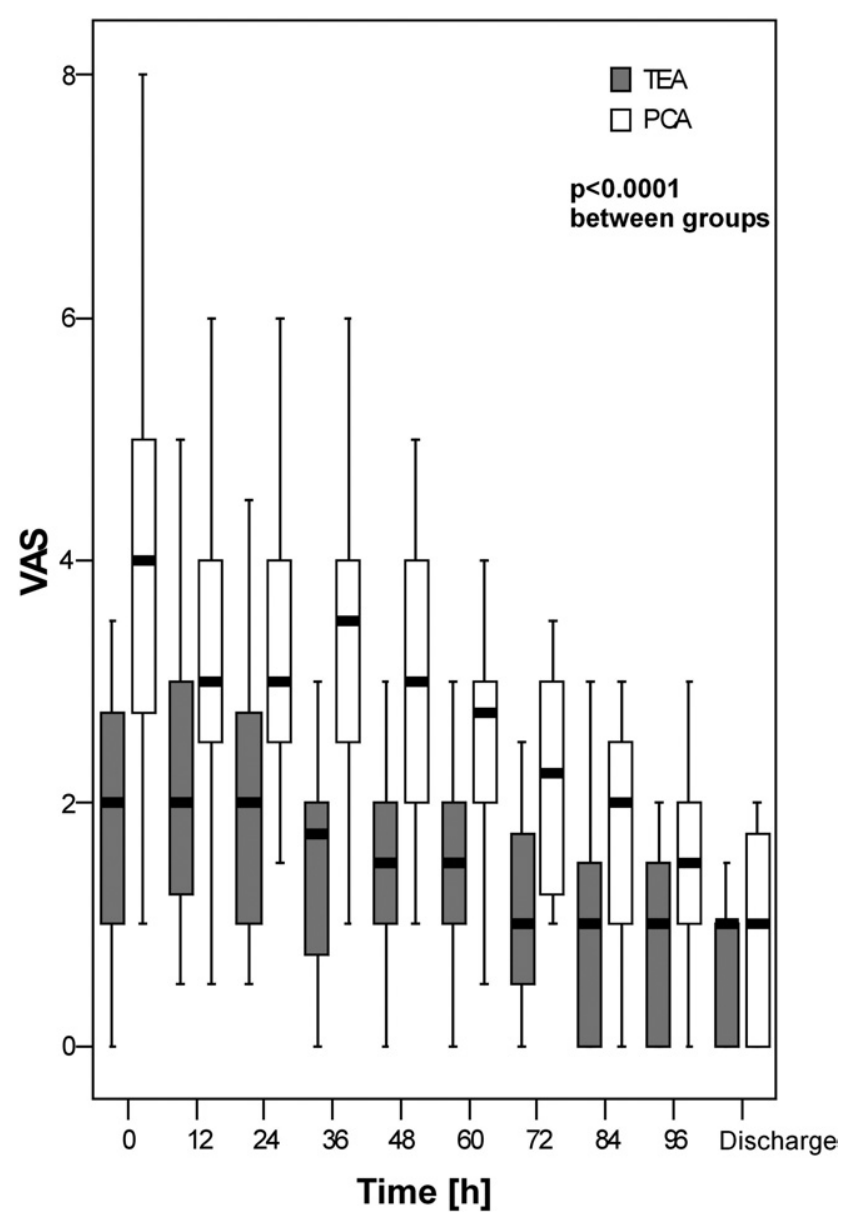

Figure 1. Higher postoperative pain scores (visual analog scale) were reported in patients treated with patient-controlled analgesia than those in patients treated with thoracic epidural analgesia after pectus excavatum repair $(P \leq .0001)$. Pain decreases over time $(P \leq .0001)$ in both groups, with a parallel course of the 2 curves. In the box-and-whiskers plot minimum, maximum, first, and third quartiles and the median are depicted.

ward). Nausea (presence or absence of) and pruritus were assessed by a nurse interviewing the patient. Time points were the end of anesthesia ( 0 hours), every 12 hours until the 96-hour postoperative time point, and discharge. Additional pain medication requests were assessed according to the same schedule. Local inflammation signs at the site of venipuncture and the epidural catheter were assessed daily by a nurse on the ward. The presence or absence of supplemental oxygen was recorded daily.

At discharge, both 3 and 6 months postoperatively, patients were interviewed as to whether they would choose the same form of anesthesia and perioperative pain management again and whether they experienced any limitations or pain caused by the operation.

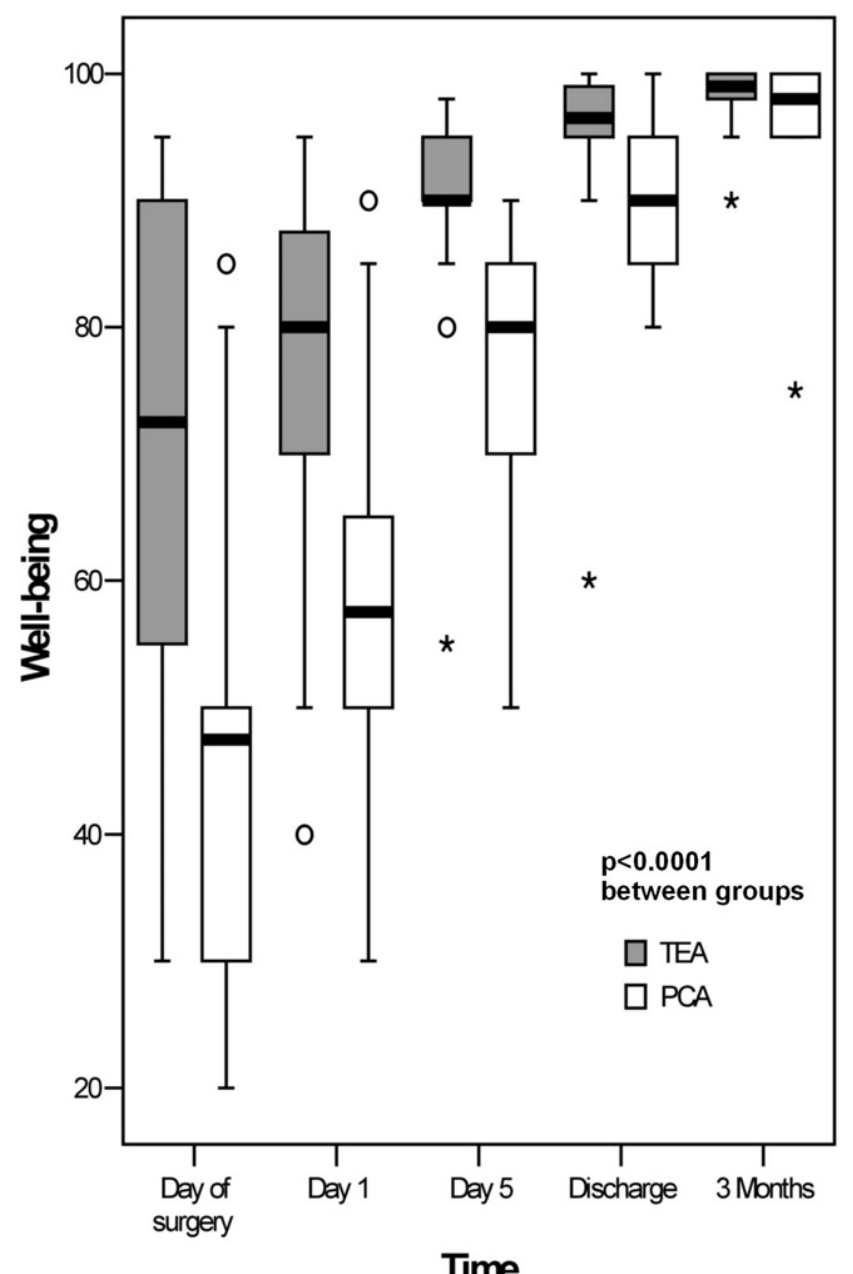

$\underset{0}{\cos }$

Figure 2. Higher ratings of well-being at a maximum value of $\mathbf{1 0 0}$ for highest well-being were reported in the thoracic epidural analgesia group after pectus excavatum repair, compared with those in the intravenous patient-controlled analgesia group $(P \leq$ .0001). In the box-and-whiskers plot minimum, maximum, first, and third quartiles and the median are depicted. Circles and asterisks mark outliers and extreme outliers.

\section{Statistical Analysis}

Statistical analysis was performed with SPSS 12.0.1 (SPSS, Inc, Chicago, Ill) and SAS 9.1 (SAS Institute, Inc, Cary, NC) software. For group comparison of categoric data, the Fisher exact test was used. Nonparametric multivariable analysis of variance for longitudinal data in a 2-factorial design (first factor: TEA vs PCA; second factor: time) was applied for the VAS and well-being scores. ${ }^{10}$ Incidence of side effects and the need for additional pain medication was examined by means of logistic regression. The generalized estimating equation method was used to account for dependencies arising from multiple assessments of the same patient (SAS, procedure Genmod). 
Table 1. Patient characteristics

\begin{tabular}{|c|c|c|c|}
\hline & PCA group $(n=20)$ & TEA group $(n=20)$ & $P$ value \\
\hline Age (y) & $16.7 \pm 5.2$ & $14.8 \pm 4.2$ & NS \\
\hline $\operatorname{Sex}(\mathrm{M} / \mathrm{F})$ & $17 / 3$ & $15 / 5$ & NS \\
\hline Height $(\mathrm{cm})$ & $170.7 \pm 15.5$ & $169.9 \pm 16.2$ & NS \\
\hline Body weight (kg) & $56.7 \pm 15.1$ & $53.7 \pm 15.8$ & NS \\
\hline Vertebral index* & $32.05 \pm 3.62$ & $31.85 \pm 4.15$ & NS \\
\hline Duration of operation (min) & $96.1 \pm 21.8$ & $97.4 \pm 19.9$ & NS \\
\hline Time between end of operation and extubation (min) & $18.8 \pm 8.7$ & $13.1 \pm 9.8$ & NS \\
\hline Intraoperative fentanyl $(\mu \mathrm{g} / \mathrm{kg})$ & $12.4 \pm 1.8$ & $3.8 \pm 0.7$ & $\leq .001$ \\
\hline Hospital length of stay $(d)$ & $9.5 \pm 1.9$ & $8.4 \pm 1.5$ & NS \\
\hline
\end{tabular}

Data are presented as means \pm standard deviation, except for sex. Statistical analysis was done with Mann-Whitney tests. Sex is presented as counts, and the Fisher exact test was used. PCA, Patient-controlled analgesia; TEA, thoracic epidural anesthesia; NS, not significant. *Vertebral index: (Vertebral diameter $(V D) \times 100 /$ Sagittal diameter $(S D)+V D$.

\section{Results}

Patients treated with a thoracic epidural catheter after pectus excavatum repair reported lower postoperative pain scores (Figure 1) and rated their well-being higher (Figure 2) than did patients treated with intravenous PCA containing morphine. Postoperative pain scores in the intravenous PCA group were higher despite higher intraoperative fentanyl use in the intravenous PCA group (Table 1). Additionally, the intravenous PCA group more often required supplemental oxygen $(P=.0005)$ and additional pain medication up to 72 hours postoperatively $(P<.0001$, Figure 3$)$. No difference between groups was detectable for sedation $(P=.37)$, nausea $(P=.10)$, and pruritus $(P=.72$, Figure 3$)$. There were no technical difficulties during placement, and no epidural catheter had to be removed because of inflammation at the site of insertion. Patient acceptance of both methods of postoperative pain therapy was excellent. After 3 and 6 months of postoperative follow-up, 3 patients in the intravenous PCA group but none in the thoracic epidural catheter group would choose a different form of analgesia for this operative procedure $(P=.23)$. One patient in the intravenous PCA group reported mild thoracic pain after 6 months (VAS score, 2).

Both groups were comparable except for intraoperative fentanyl use (Table 1).

\section{Discussion}

In this prospective randomized study comparing postoperative pain with either intravenous morphine PCA or continuous thoracic epidural analgesia after minimally invasive pectus excavatum repair, we found lower postoperative pain scores and higher well-being in the thoracic epidural group. Results of this study in adolescent patients are consistent with studies on postoperative pain in adults with epidural analgesia, ${ }^{11,12}$ favoring epidural analgesia over other types of postoperative analgesia. In children results of a literature search are more conflicting; however, different surgical procedures might influ- ence the efficacy of postoperative pain management. In posterior spinal fusion surgery, 2 studies did not show any superiority of thoracic epidural analgesia over intravenous PCA in adolescent patients, ${ }^{13,14}$ whereas Blumenthal and coworkers ${ }^{15}$ found better postoperative pain control and higher patient satisfaction with epidural analgesia.

Although neurological complications related to thoracic epidural catheterization are feared by anesthesiologists, a predicted risk of $0.07 \%$ of permanent neurological complications is estimated in adults. ${ }^{16}$ The available data for children and adolescents reporting the risk of neurological complications related to thoracic epidural catheterization are scarce. In a French survey involving more than 15,000 central blocks, mostly during general anesthesia, Giaufré and colleagues ${ }^{17}$ similarly report a low incidence of adverse events with only minor complications, but most of the blocks were caudal blocks. To minimize the risk of neurologic damage, we performed the placement of thoracic epidural catheters after achievement of local anesthesia in awake patients before surgical intervention.

Although our study was not designed to detect differences in pulmonary outcome, we observed less use of supplementary oxygen in the thoracic epidural group, despite a rather high threshold (oxygen saturation < 94\%) for supplemental oxygen administration. This observation might be explained by a difference in the incidence of postoperative atelectasis. Reduced incidence rates of atelectasis during epidural analgesia compared with systemic opioids are reported in a meta-analysis. ${ }^{18}$

Experiences of pain during childhood might increase the pain response during subsequent procedures. ${ }^{19}$ Therefore the quality of postoperative pain control seems to be a key issue, especially in children. Cucchiaro and colleagues ${ }^{20}$ showed that after major operations, children even seem to accept a higher rate of nausea and vomiting for superior pain control. However, superior analgesia did not result in a 


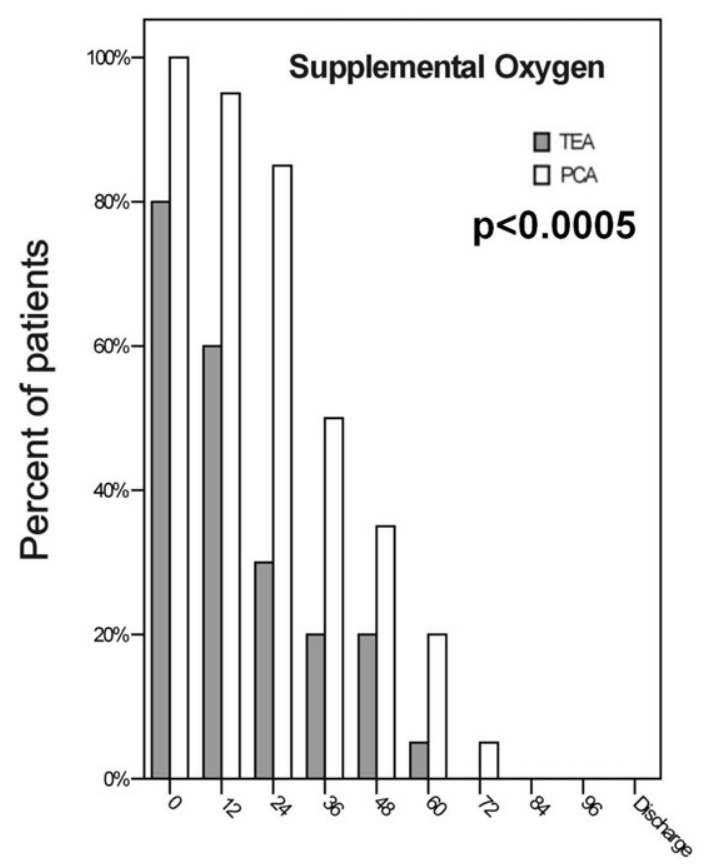

A

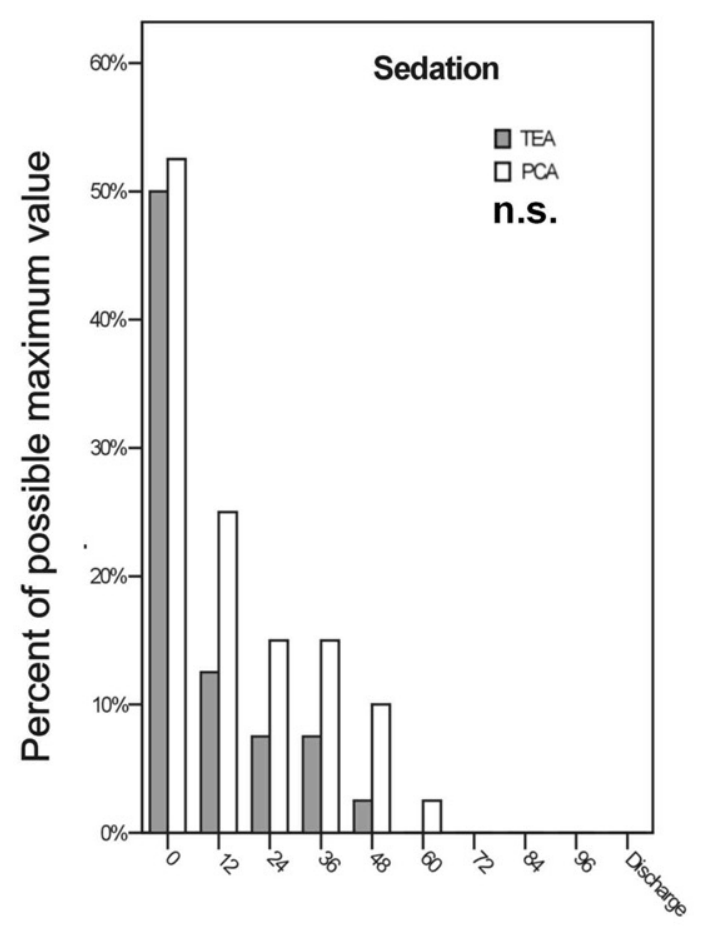

C

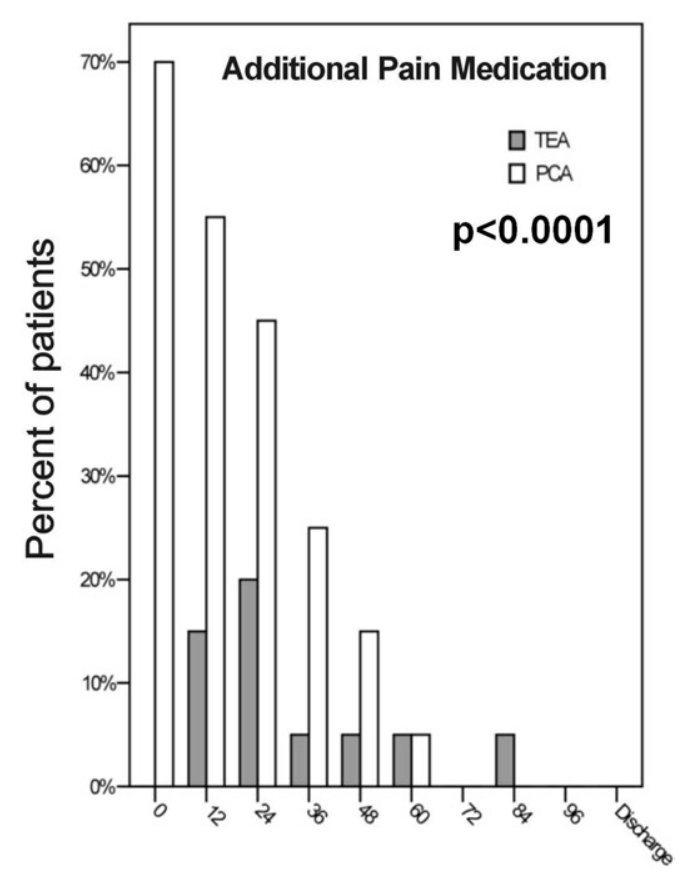

B

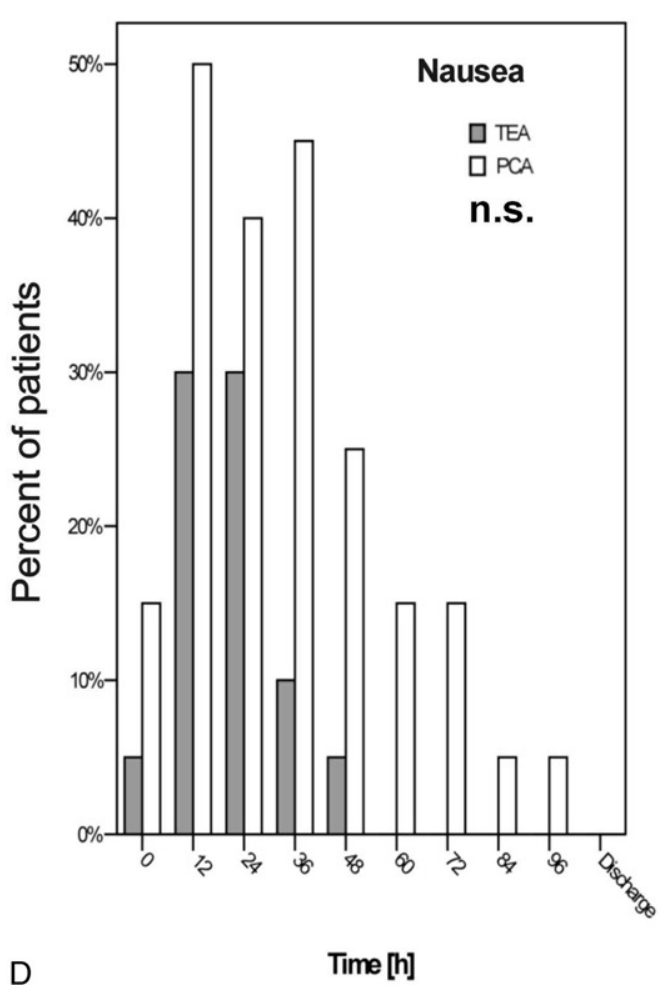

Figure 3. Side effects and additional pain medication: A, supplemental oxygen (percentage of patients); B, additional pain medication (percentage of patients); $C$, sedation $(100 \%=$ maximal possible value; ie, all patients have a score of 2); $D$, nausea (percentage of patients). In patients treated with patient-controlled analgesia, supplemental oxygen $(P=.0005)$ and additional pain medication $(P \leq .0001)$ were required more often than in patients treated with thoracic epidural analgesia after pectus excavatum repair. No difference for sedation $(P=.37)$ and nausea $(P=.10)$ was found between groups. 
higher incidence of side effects in our trial. We therefore conclude that thoracic epidural analgesia is superior to intravenous PCA in adolescents undergoing minimally invasive pectus excavatum repair.

We thank Robert Greif, MD, and the nurses of the Department of Pediatric Surgery, Sozialmedizinisches Zentrum Ost-Donauspital, for supporting this study.

\section{References}

1. Nuss D, Kelly RE Jr, Croitoru DP, Katz ME. A 10-year review of a minimally invasive technique for the correction of pectus excavatum. J Pediatr Surg. 1998;33:545-52.

2. Hebra A, Swoveland B, Egbert M, Tagge EP, Georgeson K, Biemann Othersen $\mathrm{H} \mathrm{Jr}$, et al. Outcome analysis of minimally invasive repair of pectus excavatum: review of 251 cases. J Pediatr Surg. 2000;35: 252-8.

3. Croitoru DP, Kelly RE, Goretzky MJ, Lawson ML, Swoveland B, Nuss D. Experience and modification update for the minimally invasive Nuss technique for pectus excavatum repair in 303 patients. $J$ Pediatr Surg. 2002;37:437-45.

4. Park HJ, Lee SY, Lee CS, Youm W, Lee KR. The Nuss procedure for pectus excavatum. Evolution of techniques and early results on 322 patients. Ann Thorac Surg. 2004;77:289-95.

5. McBride WJ, Dicker R, Abajian JC, Vane DW. Continuous thoracic epidural infusions for postoperative analgesia after pectus deformity repair. J Pediatr Surg. 1996;31:105-8.

6. Robicsek SA, Lobato EB. Repair of pectus excavatum. Anesthetic considerations. Chest Surg Clin North Am. 2000;10:253-9.

7. Molik KA, Engum SA, Rescorla FJ, West KW, Scherer LR, Grosfeld JL. Pectus excavatum repair: experience with standard and minimal invasive techniques. J Pediatr Surg. 2001;36:324-8.

8. Inge TH, Owings E, Blewett CJ, Baldwin CE, Cain WS, Hardin W, et al. Reduced hospitalization cost for patients with pectus excavatum treated using minimally invasive surgery. Surg Endosc. 2003;17: 1609-13.
9. Jacobs JP, Quintessenza JA, Morell VA, Botero LM, van Gelder HM, Tchervenkov CI. Minimally invasive endoscopic repair of pectus excavatum. Eur J Cardiothorac Surg. 2002;21:869-73.

10. Brunner E, Langer F. Nichtparametrische Analyse longitudinaler Daten. Vienna: R. Oldenbourg Verlag; 1999. p. 108.

11. Block BM, Liu SS, Rowlingson AJ, Cowan AR, Cowan JA, Wu CL. Efficacy of postoperative epidural analgesia. A meta-analysis. JAMA. 2003;290:2455-63.

12. Wu CL, Cohen SR, Richman JM, Rowlingson AJ, Courpas GE, Cheung K, et al. Efficacy of postoperative patient-controlled and continuous epidural analgesia versus intravenous patient-controlled analgesia with opioids: a meta-analysis. Anesthesiology. 2005;103: 1079-88.

13. Cassadry JF, Lederhaas G, Cancel DD, Cummings RJ, Loveless EA. A randomized comparison of the effects of continuous thoracic epidural analgesia and intravenous patient-controlled analgesia after posterior spinal fusion in adolescents. Reg Anesth Pain Med. 2000;25:246-53.

14. O'Hara J Jr, Cywinski JB, Tetzlaff JE, Xu M, Gurd AR, Andrish JT. The effect of epidural vs intravenous analgesia for posterior spinal fusion surgery. Pediatr Anesth. 2004;14:1009-15.

15. Blumenthal S, Nadig M, Borgeat A, Min K. Postoperative analgesia after anterior correction of thoracic scoliosis: a prospective randomised study comparing continuous double epidural catheter technique with intravenous morphine. Spine. 2006;31:1646-51.

16. Giebler RM, Scherer RU, Peters J. Incidence of neurologic complications related to thoracic epidural catheterization. Anesthesiology. 1997; 86:55-63.

17. Giaufré E, Dalens B, Gombert A. Epidemiology and morbidity of regional anesthesia in children: a one-year prospective survey of the French-language society of pediatric anesthesiologists. Anesth Analg. 1996;83:904-12.

18. Ballantyne JC, Carr DB, deFerranti S, Suarez T, Lau J, Chalmers TC, et al. The comparative effects of postoperative analgesic therapies on pulmonary outcome: cumulative meta-analyses of randomized, controlled trials. Anesth Analg. 1998;86:598-612.

19. Taddio A, Katz J, Ilersich AL, Koren G. Effect of neonatal circumcision on pain response during subsequent routine vaccination. Lancet. 1997;349:599-603

20. Cucchiaro G, Farrar JT, Guite JW, Yuelin L. What postoperative outcomes matter to pediatric patient? Anesth Analg. 2006;102: 1376-82. 